\title{
What do faculty and students really think about
}

\section{e-books?}

lan Rowlands, David Nicholas, Hamid R. Jamali and Paul Huntington

CIBER, University College London

(C) lan Rowlands, David Nicholas, Hamid R. Jamali and Paul Huntington 2007

ABSTRACT: This article reports on a large-scale survey of nearly two thousand faculty and students at one institution, University College London, and profiles their use and perceptions of ebooks. The context for the study is an action research project, CIBER's SuperBook, that will further investigate the issues raised in this initial benchmarking survey using deep log analysis and qualitative methods. The survey findings point to various ways in which user uptake and acceptance of e-books may be encouraged. Book discovery behaviour, a key issue for publishers and librarians in both print and electronic environments, emerges as a critical focus for service delivery and enhancement.

\section{Context for the research}

Until very recently, research into how digital resources are used within the academy has focused primarily on journals. Considerable steps have been made by CIBER in understanding journal user behaviour, through groundbreaking studies of Emerald, Blackwell Synergy, OhioLINK, and Oxford Open journal platforms. These studies led on the analysis of the digital "fingerprints" left by the users of electronic journals. However, the virtual scholar uses a much wider range of digitally delivered content to achieve their research, teaching and learning goals. As a first step towards a more rounded picture of how digital resources are used, we are now subjecting e-books, the new kid on the block, to the same robust approach that we have previously reserved for journals.

There is much talk about the market potential for e-books, especially in a higher education context, but few robust user studies. This is worrying because e-books have, arguably, greater potential to change the information landscape than journals. We are addressing this issue through SuperBook, an action research study, funded by Wiley, Emerald and CIBER, which involves 'dropping' about three thousand carefully selected e-texts into the UCL community and then 
watching what happens. Three publishers are featured in the study: Oxford Scholarship Online, Wiley Interscience, and Taylor \& Francis. We have created an e-book laboratory or observatory from which publishers, users, and librarians will learn, profit and exchange information. This way, hopefully, the fallouts that have occurred over e-journals will not happen with e-books. SuperBook is conceived as a pathfinder study, and it is hoped that it can be run out on a national scale.

Questionnaires, deep log analysis and interviews are the main methods being employed. This article reports on the first strand of our research, a large-scale benchmark survey of faculty and students at one institution, University College London, profiling their use and perceptions of ebooks.

\section{Survey methodology}

An email invitation to participate in the survey was distributed to all UCL staff and students (approximately 27,000) on I November 2006. The body of the email included a clickable hyperlink to the survey software (SurveyMonkey), various assurances regarding confidentiality, and an invitation to take part in a prize draw to win an iPod. By the time the survey was terminated (18 November), I,818 completions had been received, an effective response rate of at least $6.7 \%$ (we have no data on how many email messages actually arrived, there is always a possibility that some were filtered out as spam). The usual caveats apply. The industry norm for web-based survey responses is around $6-8 \%$, so we need to bear a very large non-response in mind. It is more than likely that many who responded self-selected themselves on the basis of an existing interest in e-books (or hunger for an iPod). Nonethless, it is hard to discount the views of nearly two thousand individuals from a single institution. The survey was also designed to collect data that was appropriate to individual circumstances, using a fairly complex routing structure. So, for example, people who had not used e-books before were not asked for their opinion on the features that distinguished them from conventional hard copy titles.

Encouragingly, the profile of those who completed the survey is not skewed when we consider their gender, academic status, or their faculty (Tables I-3): in none of these cases are we able to find a statistically significant difference between the composition of the sample and that of the wider UCL population. So, while the sample may be self-selected, it is at least randomly selfselected across these fundamental demographics! 
Table I: Representativeness of sample by gender ${ }^{1}$ (column percentages)

$\begin{array}{rrrr} & \text { UCL } & \text { Survey } & \% \text { points difference } \\ & \text { population } & \text { response } & \\ \text { Male } & 48.9 \% & 43.3 \% & -5.6 \\ \text { Female } & 51.1 \% & 56.7 \% & +5.6\end{array}$

Table 2: Representativeness of sample by academic status ${ }^{2}$ (column percentages)

$\begin{array}{rrrr} & \text { UCL } & \text { Survey } & \text { \% points difference } \\ & \text { population } & \text { response } & \\ \text { Undergraduate students } & 44.1 \% & 35.2 \% & -8.9 \\ \text { Graduate students } & 28.4 \% & 32.2 \% & +3.8 \\ \text { Staff } & 27.5 \% & 32.6 \% & +5.1\end{array}$

Table 3: Representativeness of sample by faculty ${ }^{3}$ (column percentages)

$\begin{array}{rrrr} & \text { UCL } & \text { Survey } & \% \text { points difference } \\ & \text { population } & \text { response } & +8.2 \\ \text { Arts and Humanities } & 11.9 \% & 20.1 \% & +5.6 \\ \text { Biomedical Sciences } & 22.8 \% & 20.4 \% & -3.3 \\ \text { Built Environment } & 6.5 \% & 3.2 \% & -3.3 \\ \text { Engineering Sciences } & 11.0 \% & 7.7 \% & -1.0 \\ \text { Life Sciences } & 4.2 \% & 3.2 \% & -0.1 \\ \text { Mathematical and Physical } & 17.2 \% & 17.1 \% & +0.9 \\ \text { Sciences } & 11.3 \% & 12.2 \% & +0.8\end{array}$

In the next phases of the SuperBook project, we hope to gain a better understanding of many of the issues benchmarked in the survey through a powerful combination of deep log analysis, interviews, and focus group discussions. Assuming that the survey is reasonably representative of

\footnotetext{
1 Pearson $\sum 2=0.63$, d.f. $=1$, distribution not significant

2 Pearson $\Sigma 2=1.67$, d.f. $=2$, distribution not significant 
the whole community (i.e. non-respondents as well as respondents), we are provisionally claiming that the findings should be interpreted as being significant at the $95 \%$ confidence level and reported at a confidence interval of plus or minus $2.2 \%$. As the project develops, we should be better placed to confirm or retract this assumption.

\section{Survey findings}

\section{Current use of e-books}

An obvious benchmark question to start with is the extent to which members of the $U C L$ community had, at the time the survey was administered, actually had experience of using e-books (Figure I), whether supplied by UCL or indeed through any other channel, such as a bookshop or the web.

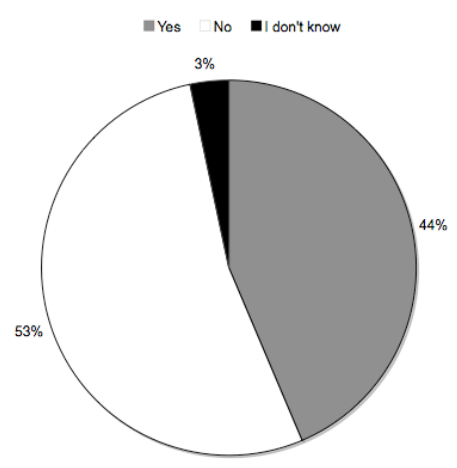

Figure I: Current use of e-books $(n=|, 8| 8)$

Users form a large minority (44\%) of the UCL community, a finding that is closely in line with other surveys (for example, a 2005 study of undergraduates at New Hall Cambridge found a 38\% penetration rate).

A number of interesting demographic patterns emerge when we look at the data for existing ebook users more closely (diversity is a strong leitmotiv in this article, as indeed in most of CIBER's recent work). For example, existing users are: 
- more likely to be dependent upon searching other libraries catalogues ${ }^{4}$

- more likely to be dependent publishers' catalogues or web sites ${ }^{5}$

- less reliant on following up references on reading lists 6

- less reliant on personal recommendations ${ }^{7}$

- more likely to be dependent Google or another popular web search engine ${ }^{8}$

- more likely to report a worse experience of UCL Library Services ${ }^{9}$

- likely to exhibit very much higher levels of awareness of UCL e-book provision ${ }^{10}$

- much more likely to be male ${ }^{11}$

- more likely to be a graduate students, less likely to be a staff member ${ }^{12}$

In fact, as one considers the above, it seems that existing e-book users are relatively independent (or at least this seems to be what they claim) of formal library provision. This is an important point that will be re-visited later in the context of book discovery behaviour.

As might well have been anticipated, age is a good predictor of e-book use (Figure 2), and the extent of this effect is very striking.

\footnotetext{
4 Pearson $\sum 2=11.92$, d.f. $=3$, distribution significant at the $1 \%$ level

5 Pearson $\sum 2=26.54$, d.f. $=3$, distribution significant at the $0.1 \%$ level

6 Pearson $\sum 2=8.29$, d.f. $=3$, distribution significant at the $5 \%$ level

7 Pearson $\sum 2=8.75$, d.f. $=3$, distribution significant at the $5 \%$ level

8 Pearson $\sum 2=25.51$, d.f. $=3$, distribution significant at the $0.1 \%$ level

9 Pearson $\sum 2=13.89$, d.f. $=5$, distribution significant at the $5 \%$ level

10 Pearson $\sum 2=92.10$, d.f. $=1$, distribution significant at the $0.1 \%$ level

11 Pearson $\sum 2=15.03$, d.f. $=2$, distribution significant at the $0.1 \%$ level

12 Pearson $\sum 2=23.62$, d.f. $=8$, distribution significant at the $1 \%$ level
} 


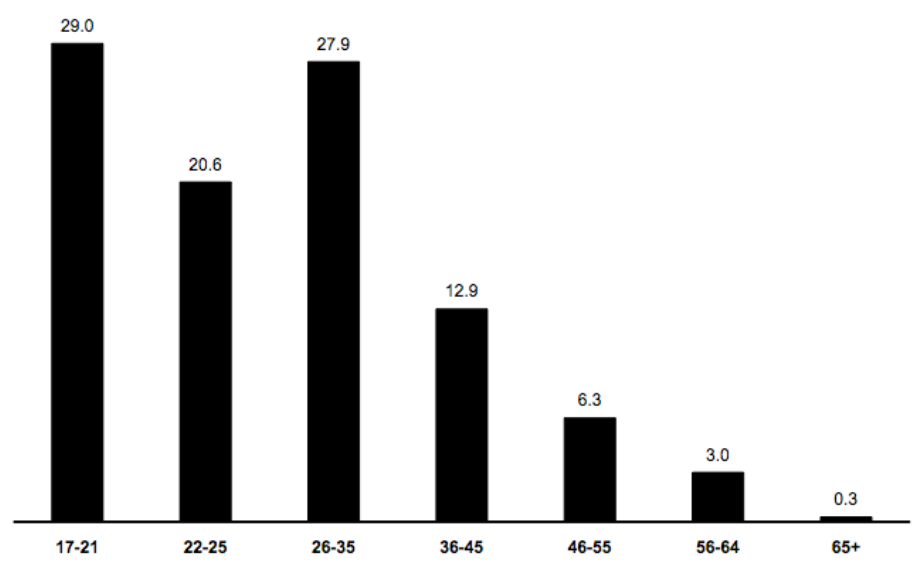

Figure 2: Current use of e-books by age group ${ }^{13}$ (users as a percentage of each age group, $n=1,655)$

The demographics of e-book use are complex, since age, gender, and broad subject interest all interact with one another in various ways. As an example, Figure 3 presents the findings of a univariate General Linear Model (GLM) analysis where gender and broad subject were held constant in relation to e-book use (for the sake of simplicity, not all subjects are shown here). For most disciplines, existing e-book users are much more likely to be male than female (i.e. to appear lower on the $y$-axis). However, in engineering and the social and historical sciences, the gender pattern reverses. Numbers are admittedly too small to make more general claims here, but this GLM analysis does point to the complexity of the demographic interactions and the need to avoid 'one-size-fits-all' prescriptions based on a superficial reading of highly aggregated data, as in so much library survey work. 


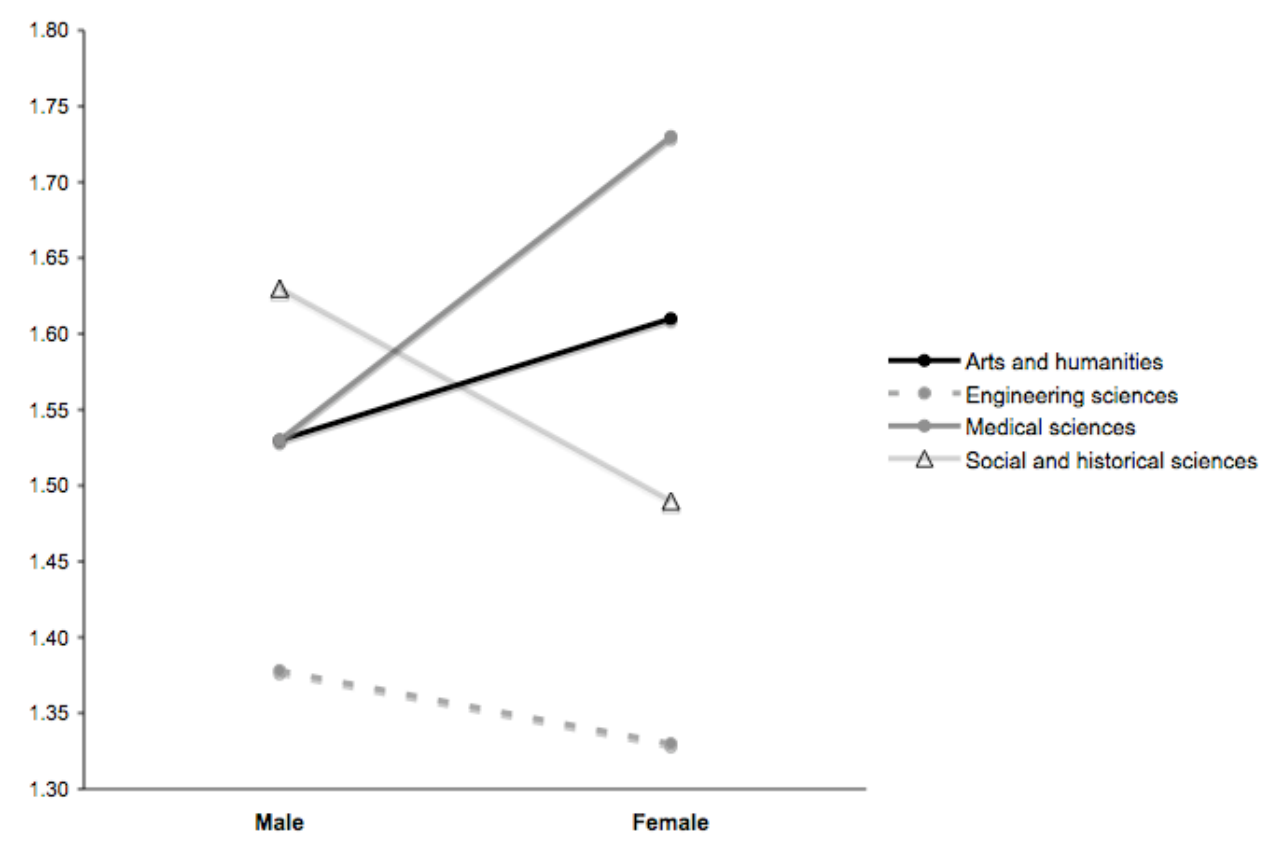

Figure 3: Current use of e-books: interaction of broad subject and gender (marginal means)

Surprisingly, perhaps, neither status (full-, part-time or occasional) nor regularity of use of print library collections are associated with existing e-book use.

Table 5 shows the findings of another more detailed analysis, this time a binomial logistic regression. The intention here is to develop a simple predictive model that speaks to whether or not someone is likely to be an existing user of e-books based on their responses to the other questions in the survey. The odds ratios in this model (Table 4, final column) show that current users of e-books are very likely to be already aware of UCL's e-book offerings (three times as likely), to be male (one and a half times more likely), and to be less than wholly satisfied with UCL's printed book collections (about 13\% more likely). These three factors enable a correct prediction to be made in $63.5 \%$ of all cases. These findings suggest that many users' interest in ebooks may have been activated by their experience at UCL, a working hypothesis that will be pursued (the effect could of course equally run in the opposite direction: having already used ebooks they then seek out this form of provision more actively in a library context). 
Table 4: Predictors of existing e-book use: a binary logistic regression Predictor

$$
\begin{array}{lllll}
\text { B Wald } & \text { d.f. } & \text { P } & \text { Odds } \\
\Sigma^{2} & & & \text { ratio }
\end{array}
$$

Step 2:

$\begin{array}{rrrrrr}\text { Q09 [Satisfaction with UCL print collections] } & -0.13 & 8.64 & \text { I } & 0.000 & 0.88 \\ \text { Q10 [Awareness of UCL e-book collections] } & 1.10 & 92.81 & \text { I } & 0.000 & 3.01 \\ \text { QI3 [Gender] } & 0.42 & 15.95 & \text { I } & 0.000 & 1.52\end{array}$

\section{Sourcing e-books}

For those currently using e-books, a key question for both publishers and librarians is how they sourced those materials in the first place? At this point in time, our survey finds that existing $\mathrm{UCL}$ e-book users are relatively independent of library provision, with a majority (6I\%) sourcing titles under their own steam (Figure 4).

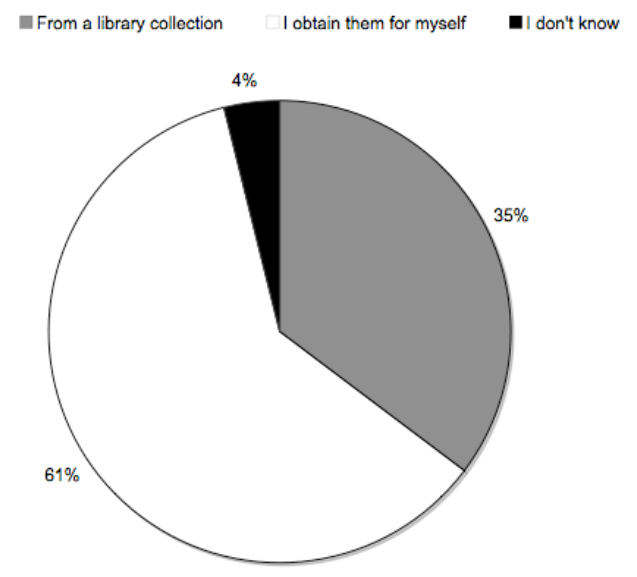

Figure 4: Sourcing e-books $(n=76 I)$ 
Again, there are pronounced gender differences, with men exhibiting a greater degree of 'library independence' than women (Figure 5). Doctoral students show the greatest degree of selfsufficiency of any of the groups, with nearly two-thirds, $65 \%$, currently obtaining their e-books for themselves.

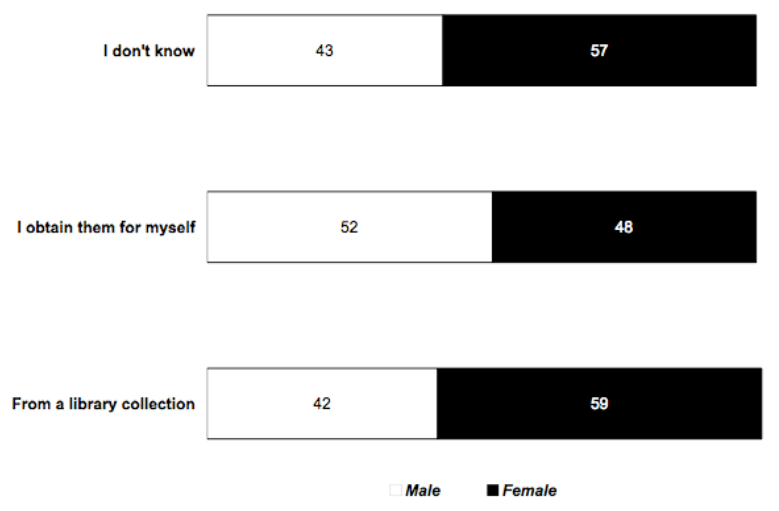

Figure 5: Sourcing e-books: gender differences (percentages within gender, $n=76 \mathrm{I}$ )

\section{Reading format preferences}

A crucial question for the widespread adoption of e-books is the issue of reading format preference. E-book users at UCL claim a strong preference for reading from screen rather than paper, and this seems to be relatively independent of their age (Figure 6).

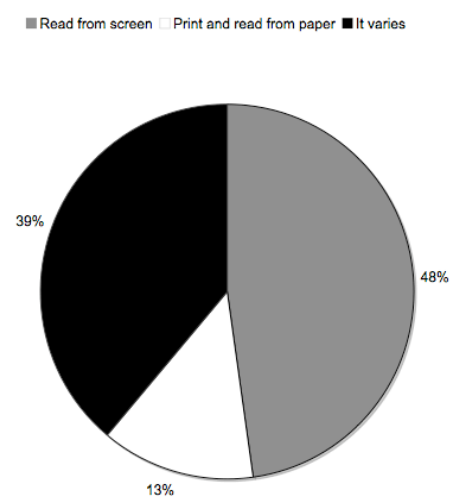

Figure 6: Reading format preferences $(n=761)$ 
The demographic profile for this question is particularly interesting:

- men say they are more likely to read from a screen than women ${ }^{14}$

- undergraduates appear to be the most likely group to read from screen ${ }^{15}$

The relationship between format preference and age is more complex than might have been anticipated (see Figure 7).

Q Read from screen $\quad$ Print and read from paper It varies

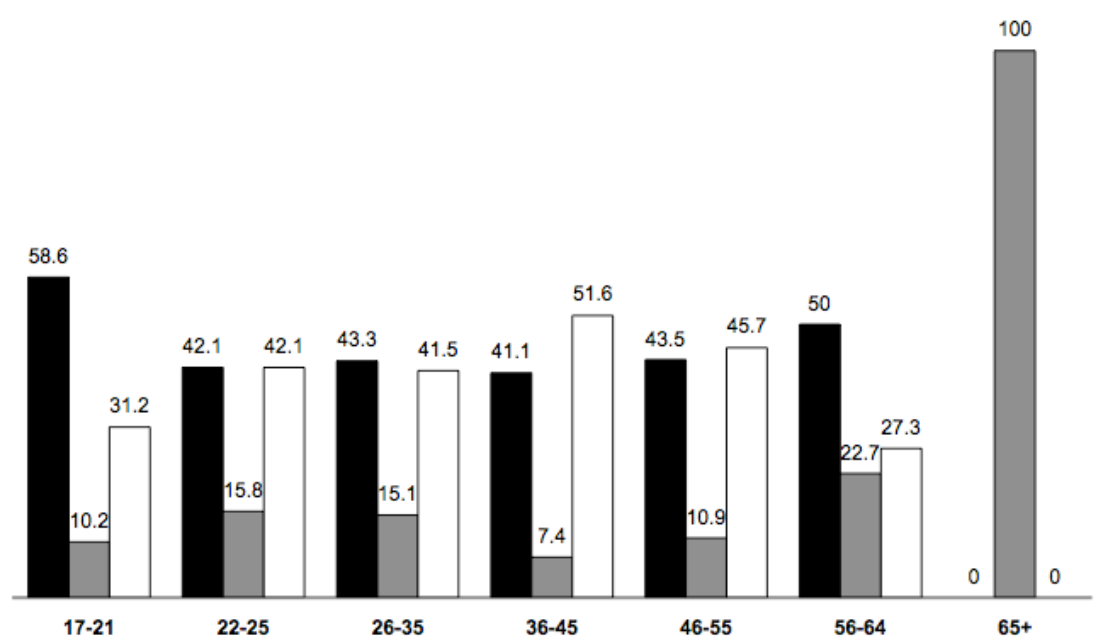

Figure 7: Reading format preferences (percentages within each age category)

The youngest group (undergraduates) shows a very marked preference for reading from screen, but the overall pattern appears not to be very age-dependent, except for a marked fall off (on the basis of a small population) after the age of 65 . These findings raise more questions than they answer: Are people really reporting their behaviour accurately? What do they mean when they say "it varies"? Why and under what circumstances? 


\section{Purpose of reading}

One of the most potent guiding principles in librarianship is "To each book its reader", a maxim coined by the famous Indian librarian (and UCL alumnus), S.R. Ranganathan. What kinds of needs do e-books meet for academics at UCL, in their professional or personal capacities?

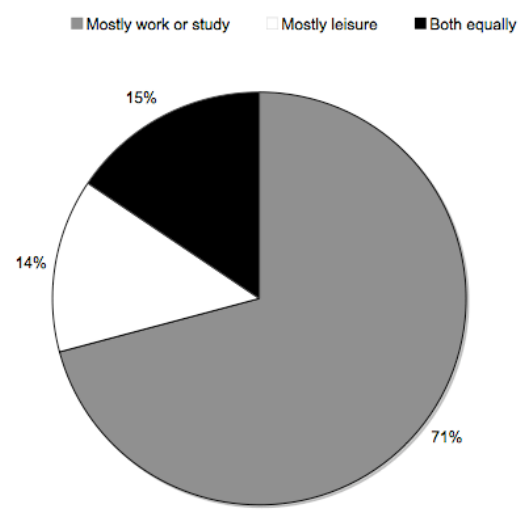

Figure 8: Purpose of reading $(n=760)$

At the time of the survey, users clearly associated e-books mainly with work and study rather than leisure. The extent to which this finding is constrained by the availability of suitable titles, or whether it reflects deeper undercurrents is something that will be investigated further during the course of SuperBook.

There are no significant age or gender differences with respect to this issue. Part-timers (staff and students) do tend to use e-books more to support their leisure activities ${ }^{16}$, another finding that deserves closer scrutiny. Perhaps unsurprisingly, there is a strong tendency for users to read leisure materials from a computer screen but print out the contents of work or study-based materials ${ }^{17}$. 
Table 5: Purpose and sources of e-book readings (row percentages)

$\begin{array}{rrrrr}\text { Purpose } & \begin{array}{r}\text { Mostly for } \\ \text { personal }\end{array} & \begin{array}{r}\text { Mostly for work } \\ \text { or study }\end{array} & \text { Both equally } & \text { Don't now } \\ \text { reading } & 4.8 \% & 82.7 \% & 12.5 \% & 0.2 \% \\ \text { I get them from a library collection } & 17.8 \% & 63.6 \% & 18.5 \% & 0.2 \% \\ \text { I obtain them for myself } & 13.8 \% & 70.5 \% & 15.4 \% & 0.3 \% \\ \text { All responses } & & & \end{array}$

The findings in Table 5 show that libraries are very much the preferred source for e-book materials relating to work or study and that users generally tend to find other sources for their leisure reading. Finding other ways into this question will be important, again because the answers could be shaped as much by title availability as by any innate preference.

\section{Types of e-books used}

A more detailed breakdown of the particular types of e-books used is presented as Figure 9. (Note that respondents were invited to tick as many boxes as applied, thus the total responses is greater than the number of respondents).

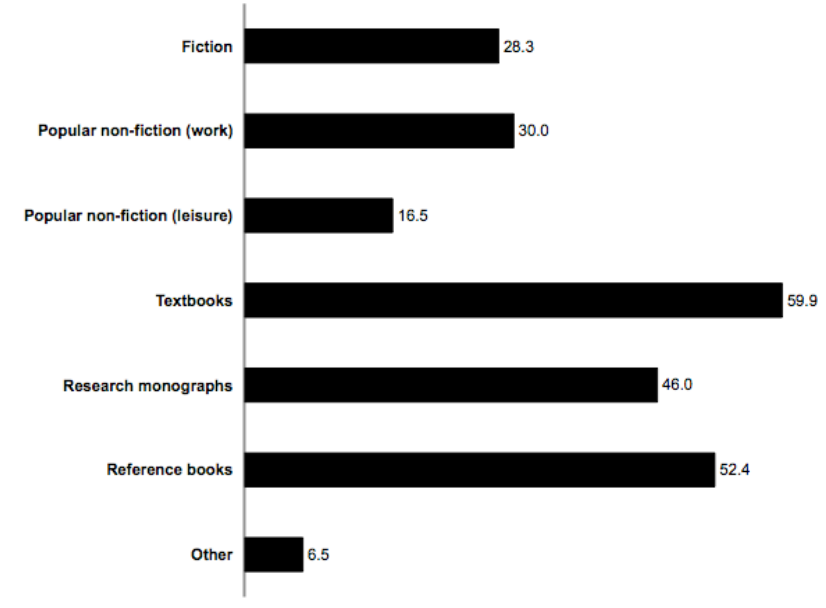

Figure 9: Types of e-books used (percentages of respondents, $n=759$ )

Textbooks are clearly the most popular form for academic users, followed by reference works. 
This question offers some valuable insights into the current academic market for e-books and these are explored further in Tables 6-8. Highlights include a strong preference for popular nonfiction by men (Table 6), and for fiction and popular non-fiction amongst undergraduates (Table 7). The findings in Table 8 suggest that there is strong competition from non-library sources (i.e. people buy or obtain them on their own account) across all e-book formats.

Table 6: Types of e-books used by gender (column percentages)

Men Women

Fiction $\quad 27.9 \% \quad 28.2 \%$

$\begin{array}{rrr}\begin{array}{r}\text { Popular non-fiction unrelated to work } \\ \text { or study }\end{array} & 19.0 \% & 13.9 \% \\ \begin{array}{r}\text { Popular non-fiction unrelated to work } \\ \text { or study }\end{array} & 29.3 \% & 30.8 \% \\ \text { Textbooks } & 62.6 \% & 57.9 \% \\ \text { Research monographs } & 49.4 \% & 43.2 \% \\ \text { Reference works } & 53.9 \% & 55.0 \%\end{array}$

Table 7: Types of e-books used by academic status (column percentages)

\begin{tabular}{|c|c|c|c|c|}
\hline & $\begin{array}{r}\text { Undergraduat } \\
\text { es }\end{array}$ & Masters & Doctoral & $\begin{array}{r}\text { Academic } \\
\text { and research } \\
\text { staff }\end{array}$ \\
\hline Fiction & $30.3 \%$ & $24.8 \%$ & $24.4 \%$ & $23.6 \%$ \\
\hline $\begin{array}{r}\text { Popular non-fiction unrelated to work } \\
\text { or study }\end{array}$ & $17.8 \%$ & $12.4 \%$ & $15.6 \%$ & $14.2 \%$ \\
\hline $\begin{array}{r}\text { Popular non-fiction unrelated to work } \\
\text { or study }\end{array}$ & $39.8 \%$ & $28.7 \%$ & $20.0 \%$ & $20.3 \%$ \\
\hline Textbooks & $57.6 \%$ & $63.6 \%$ & $68.1 \%$ & $55.4 \%$ \\
\hline Research monographs & $32.2 \%$ & $46.5 \%$ & $60.0 \%$ & $59.5 \%$ \\
\hline Reference works & $53.8 \%$ & $49.6 \%$ & $54.1 \%$ & $56.1 \%$ \\
\hline
\end{tabular}


Table 8: Types of e-books used by source (column percentages)

$\begin{array}{rrrr} & \begin{array}{r}\text { I get them from } \\ \text { a library } \\ \text { collection }\end{array} & \begin{array}{r}\text { I obtain them for } \\ \text { myself }\end{array} & \text { All responses } \\ \text { Fiction } & 8.0 \% & 14.4 \% & 12.1 \% \\ \text { Popular non-fiction } & 13.9 \% & 12.7 \% & 12.8 \% \\ \text { (work) } & & & 7.0 \% \\ \text { Popular non-fiction } & 4.9 \% & 8.6 \% & \\ \text { (leisure) } & & & 25.5 \% \\ \text { Textbooks } & 26.7 \% & 23.8 \% & 19.6 \% \\ \text { Research monographs } & 22.2 \% & 18.4 \% & 23.1 \% \\ \text { Reference books } & 24.2 \% & 22.1 \% & \end{array}$

\section{Advantages and disadvantages of e-books}

E-books and conventional print titles offer users a very different kind of experience and this question explores user perceptions of the relative advantages and disadvantages of each format across a range of factors. The precise form of the question was that respondents were invited to tick one of the following three options for each factor:

$\mathrm{I}=$ 'e-books are better'

$2=$ 'printed books are better'

$3=$ 'I don't know'

Again, only those who had actually used e-books were surveyed.

The data in Figure 10 reveal users' perceptions of the advantages (positive values) and disadvantages (negative values) of e-books when compared with conventional hard copy titles (the units are percentage point differences and 'don't knows' are excluded for ease of assimilating the essential message). 


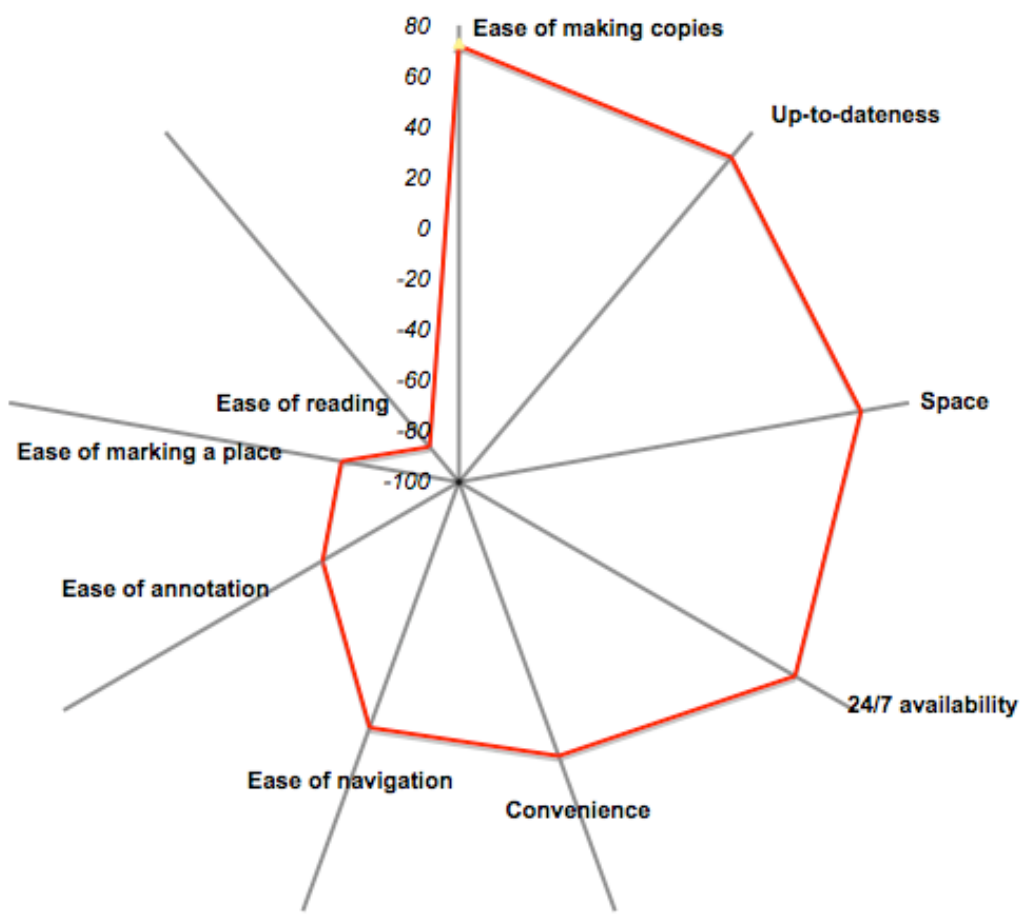

Figure 10: Advantages and disadvantages of e-books (percentage point differences, e-books and print, $n=760$ )

E-books clearly compare very unfavourably indeed with print titles for perceived ease of reading. The benefits of e-books cluster around convenience: ease of making copies, perceived up-todateness, space-saving, and around the clock availability. That hard copy is so decisively favoured in terms of ease of reading is a little surprising given the responses reported earlier regarding reading format preferences (Figure 6) and suggests that more work on actual, rather than selfreported, reading behaviour is urgently needed. 
Confidence in the relative up-to-dateness advantage of e-books declines markedly with age ${ }^{18}$, similarly, their around-the-clock availability ${ }^{19}$. There is a big difference between men and women in respect of features and functionality: men tend to rate these aspects much more highly ${ }^{20}$.

\section{Current use of library print collections}

All respondents rejoined the survey at this point, where the attention shifts from actual experience of using e-books to profiling current use and satisfaction with UCL Library Services' print collections and general book discovery behaviour.

The UCL community is segmented in Figure II by their current use of library print titles.

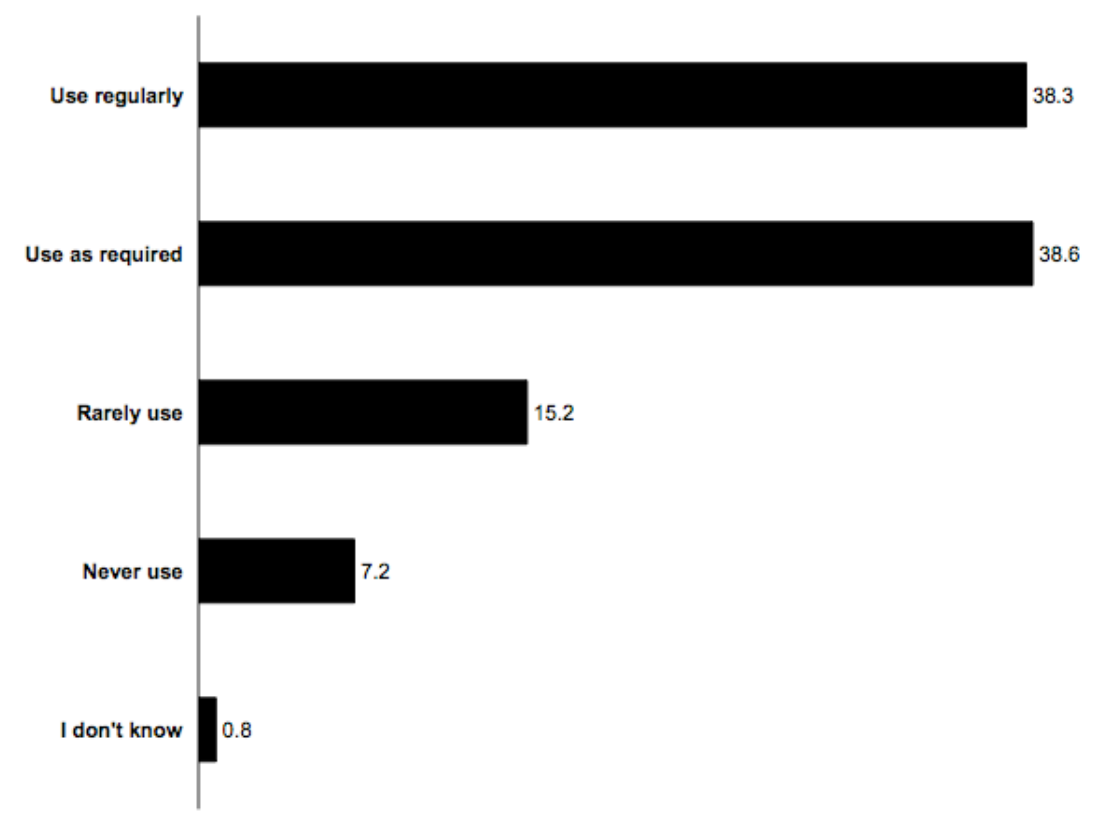

Figure I I: Current use of library print collections (percentages, $n=I, 673$ )

The two critical demographics relating to the intensity of print collection use are gender and age:

18 Pearson $\sum 2=45.30$, d.f. $=14$, distribution significant at the $0.1 \%$ level

19 Pearson $\sum 2=22.10$, d.f. $=14$, distribution significant at the $1 \%$ level

20 Pearson $\sum 2=11.66$, d.f. $=4$, distribution significant at the $5 \%$ level 
- women (42\%) are much more likely to classify themselves as 'regular users' than men $(35 \%)^{21}$

- regular use peaks at $22-25$ years (44\%) then declines to a minimum of $28.7 \%(46-55)^{22}$

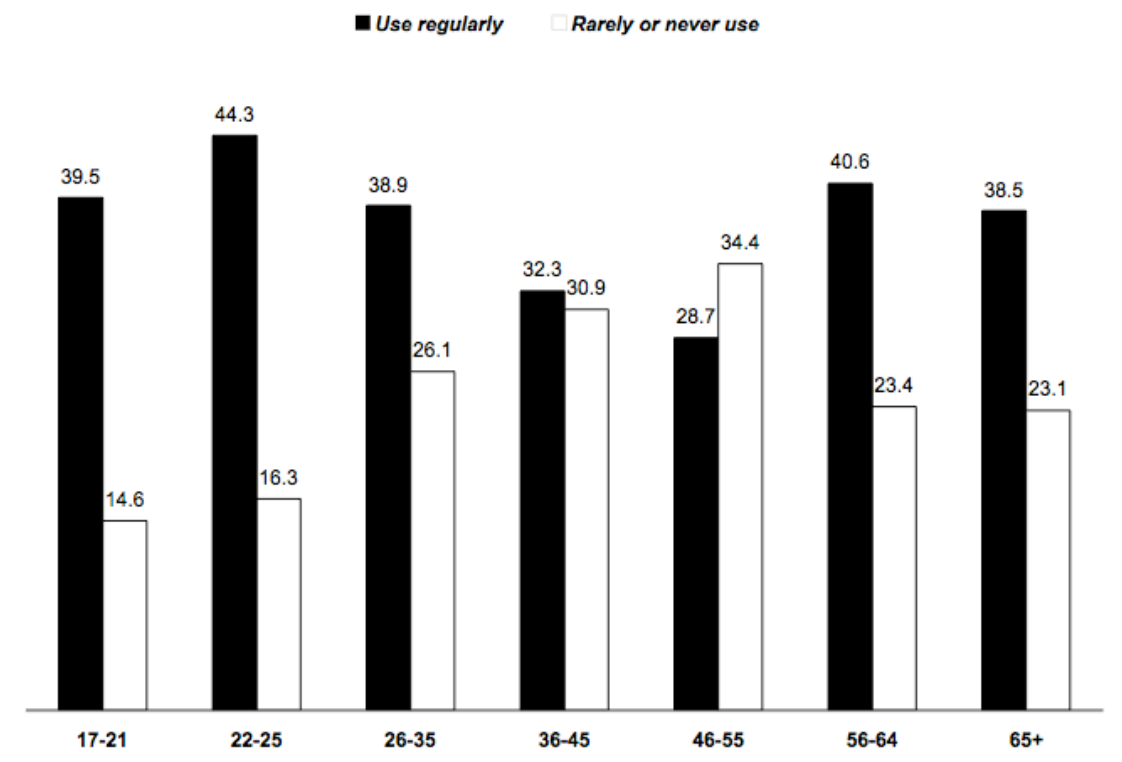

Figure 12: Current use of library print collections by age (percentages, $n=I, 673$ )

The extent of the age effect on intensity of print collection use is starkly portrayed in Figure 12. This is hardly unexpected, since the information needs of undergraduates and professors emeriti are hardly likely to be co-extensive! The more interesting issue is the striking switchover in behaviour in middle age and whether this will persist as we move through time, or simply disappear as a generation of digital immigrants passes by?

\section{Book discovery preferences}

The question of precisely how readers identify the books they want to read or consult is seriously under-researched in the literature, amazingly so given its significance for publishers and librarians (let alone readers). Here, we asked respondents to rate their perceived level of dependence on a range of formal and informal mechanisms for (print) book discovery. A four point scale was used 
$(I=$ 'very dependent'; 2 = 'quite dependent'; 3 = 'not very dependent'; $4=$ 'not at all dependent').

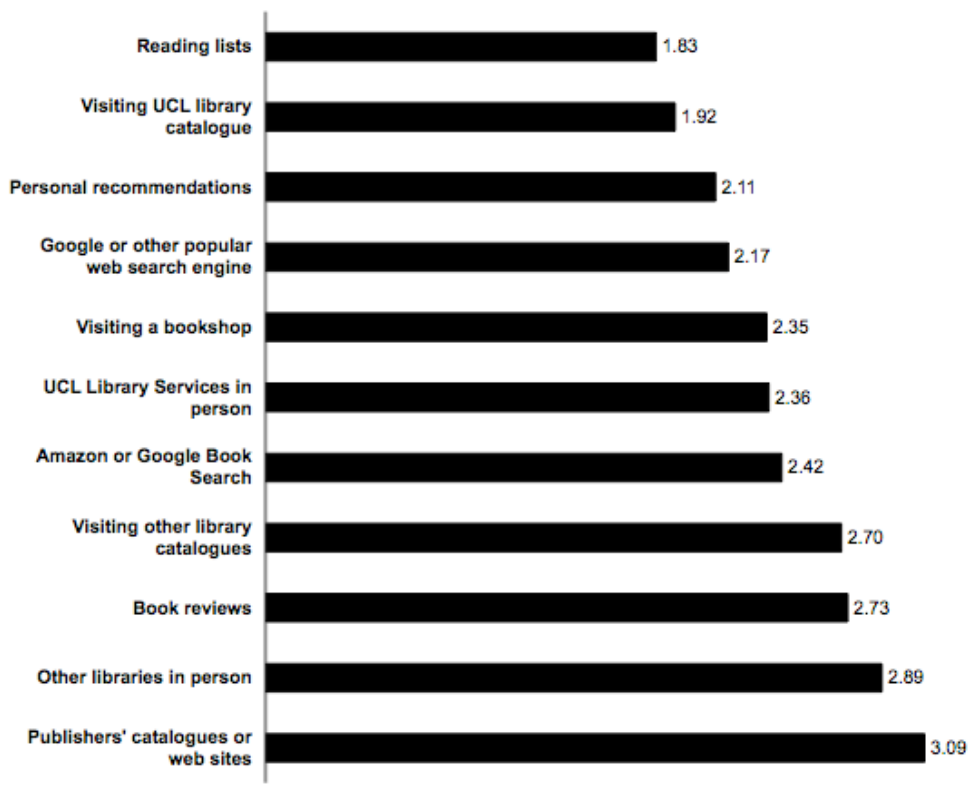

Figure 13: Book discovery preferences (mean values, $n=I, 67 \mid$ )

Book discovery behaviour is complex, and we can only scratch the surface this article.

At first glance, the findings presented in Figure 13 might suggest that individuals employ a wide range of strategies to identify the books they need for work or study. It is certainly the case that most of us do most of the things on this list at some point in our work or leisure time. However, a closer examination of the data suggests that there is real underlying structure to these preferences. Demographic factors, notably broad subject, age, and gender all play a significant role in determining which strategies tend to be emphasised.

Figure 14 is an automatic classification ${ }^{23}$ that reveals something of how book discovery behaviour is structured at UCL. This hierarchical classification was achieved by means of some fairly heavy 
number crunching: briefly, the profile of answers to this multi-part question for each and very respondent were compared with all other respondents to see if there is any discernible pattern.

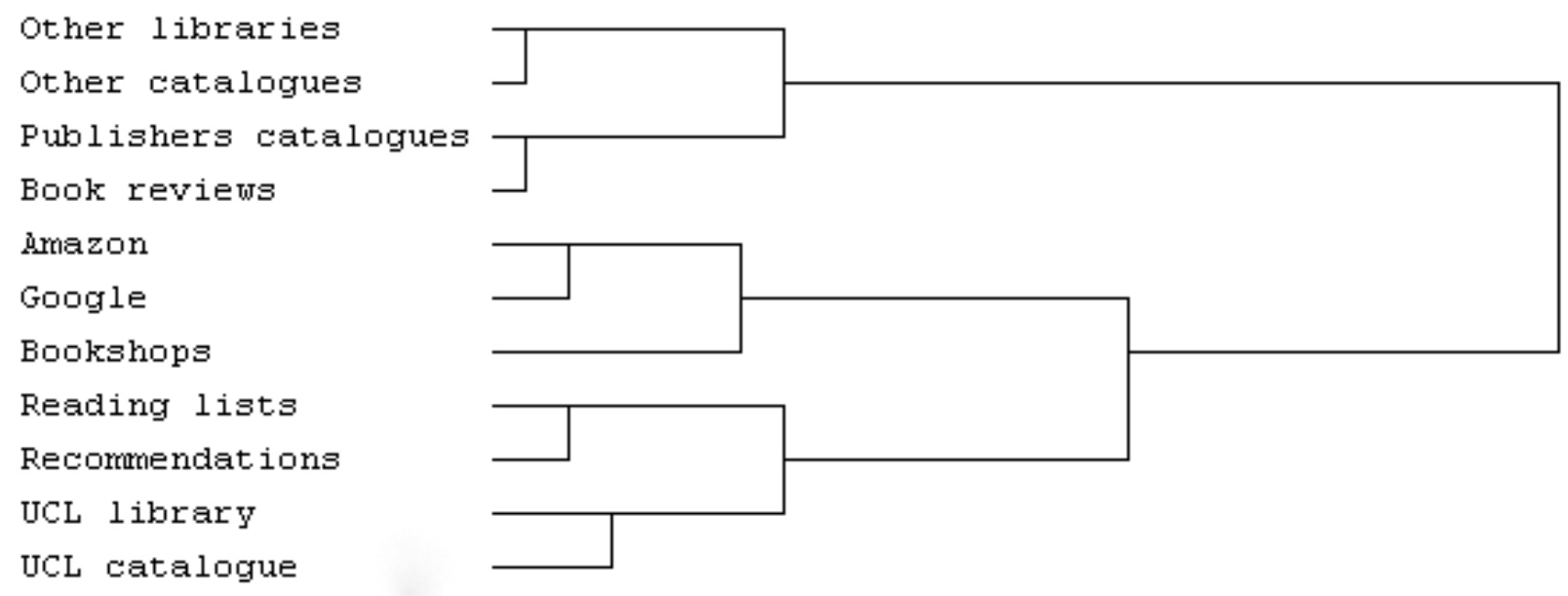

Figure 14: Automatic classification of book discovery mechanisms

Three clusters of factors are apparent. The first cluster brings together visiting other (i.e. nonUCL) libraries and catalogues, publishers' catalogues and web sites, and book reviews. These are all formal or semi-formal systems of literature control that lie outside the ambit of UCL Library Services and are suggestive of specialist research requirements. The second cluster brings together searching Amazon or Google Book Search, searching Google or other popular web sites, and visiting bookshops. This grouping suggests a fundamental mode of behaviour that is highly independent of library systems and provision. The third cluster comprises activities (following up reading lists, personal recommendation from friends and colleagues, consulting UCL Library Services in person or consulting the catalogue) that are institutionally focused. While not suggesting that any of these strategies is 'more important' than another, an interesting line of enquiry would be to see whether these archetypes have any explanatory power and if they do indeed map onto different kinds of information requirement.

That book discovery behaviour is a complex and highly structured set of activities, is further illustrated by Figures I5-18. These all illustrate very significant demographic differences that clearly have implications for service delivery. 


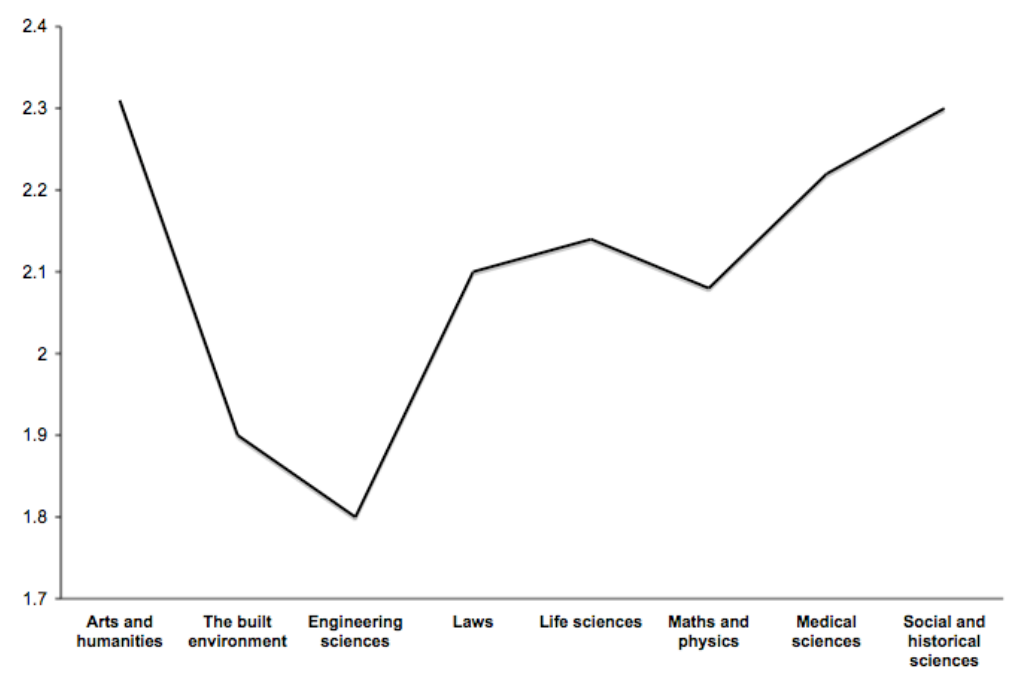

Figure I5: Dependence on Google or other search engines by broad subject ${ }^{24}$ (mean values)

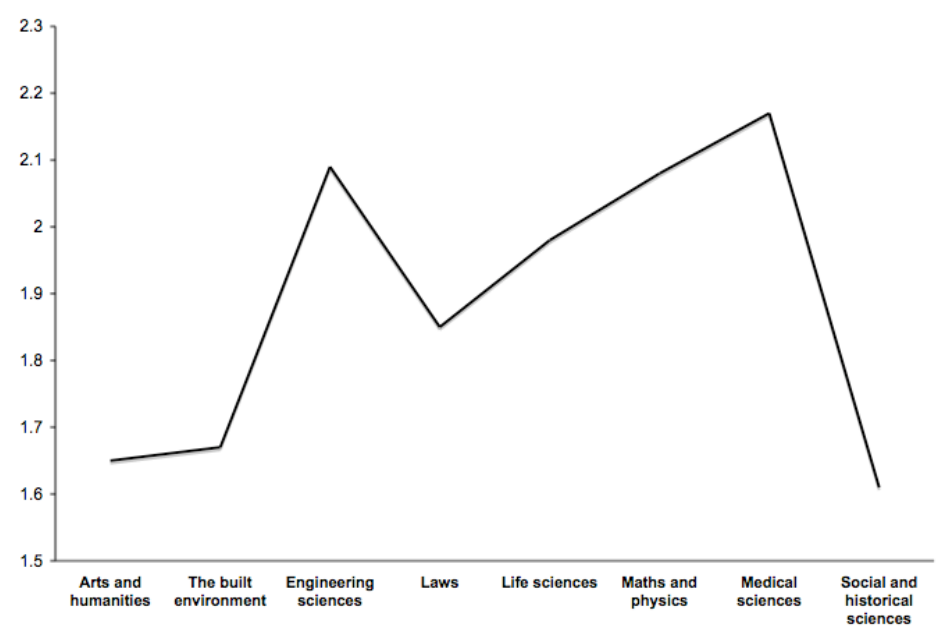

Figure 16: Dependence on UCL catalogue by broad subject ${ }^{25}$ (mean values) 


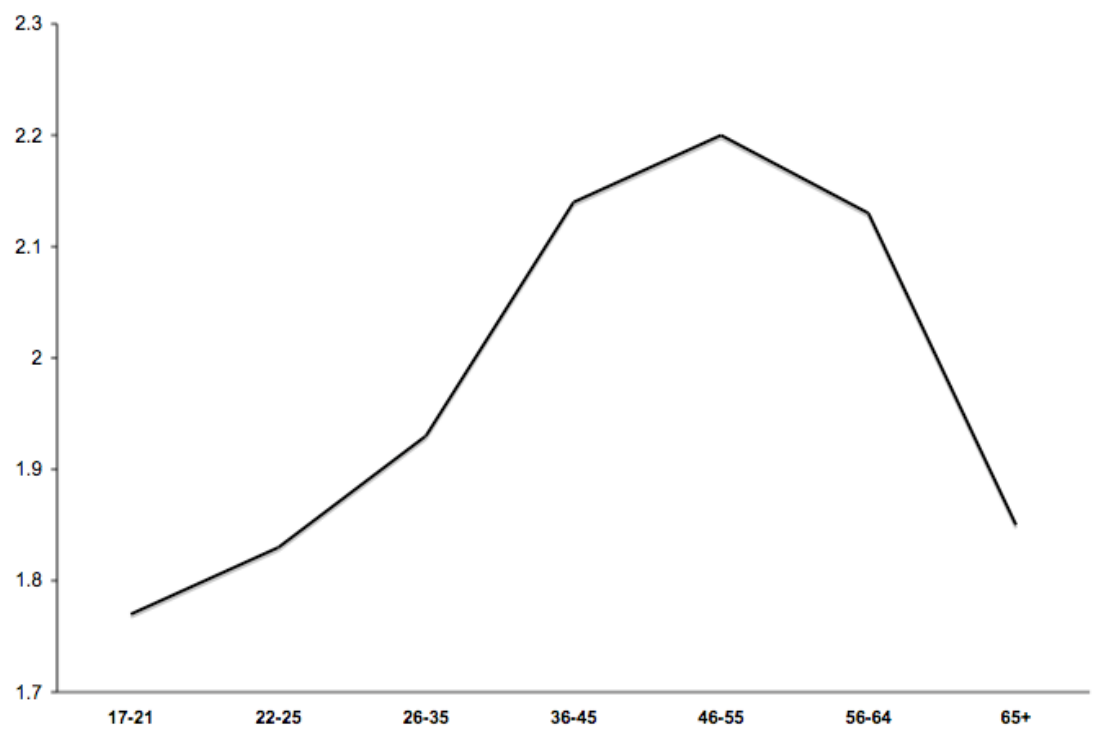

Figure 17: Dependence on UCL catalogue by age ${ }^{26}$ (mean values)

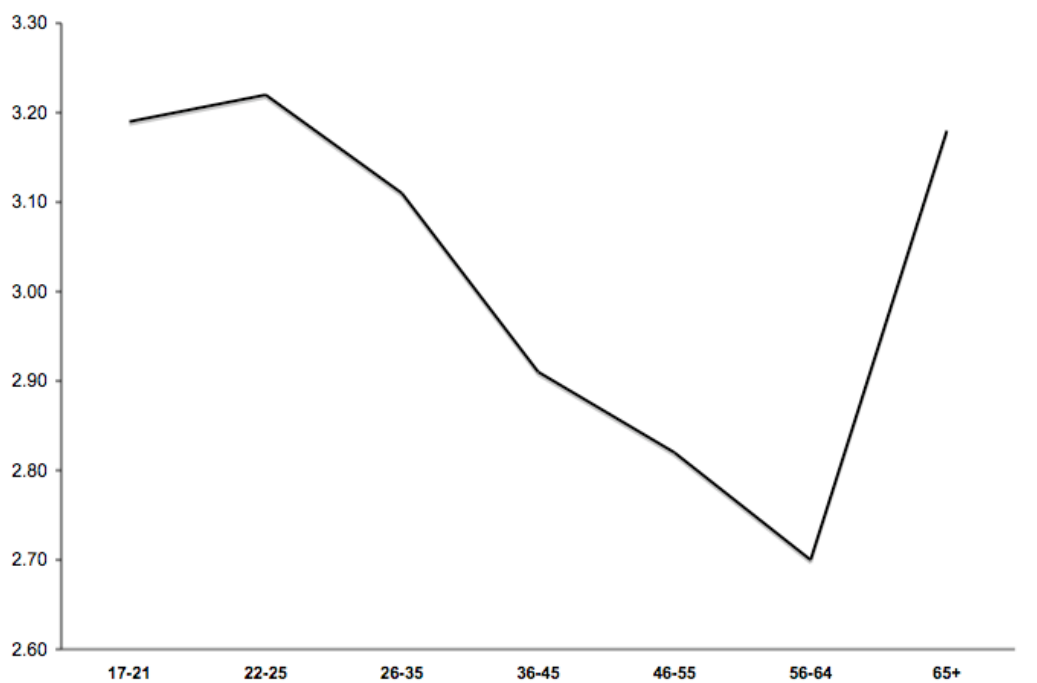

Figure 18: Dependence on publishers/ catalogues and web sites by age ${ }^{27}$ (mean values) 
Space here does not permit a fuller exploration of the issues around book discovery: we will simply note that they are complex and beg further examination. The key message is that service planning and delivery might well benefit from a better understanding of how people find books and that publishers and librarians might do well to segment their offerings in a much more sophisticated way: 'one-size-fits-all' solutions would not seem to be a good idea at all looking at the evidence here.

\section{Satisfaction with current provision of printed library books}

At some point, every library user experiences difficulty in obtaining copies of conventional printed books and so the purpose of the next question is to determine the wider institutional context within which to understand the take-up or neglect of e-books.

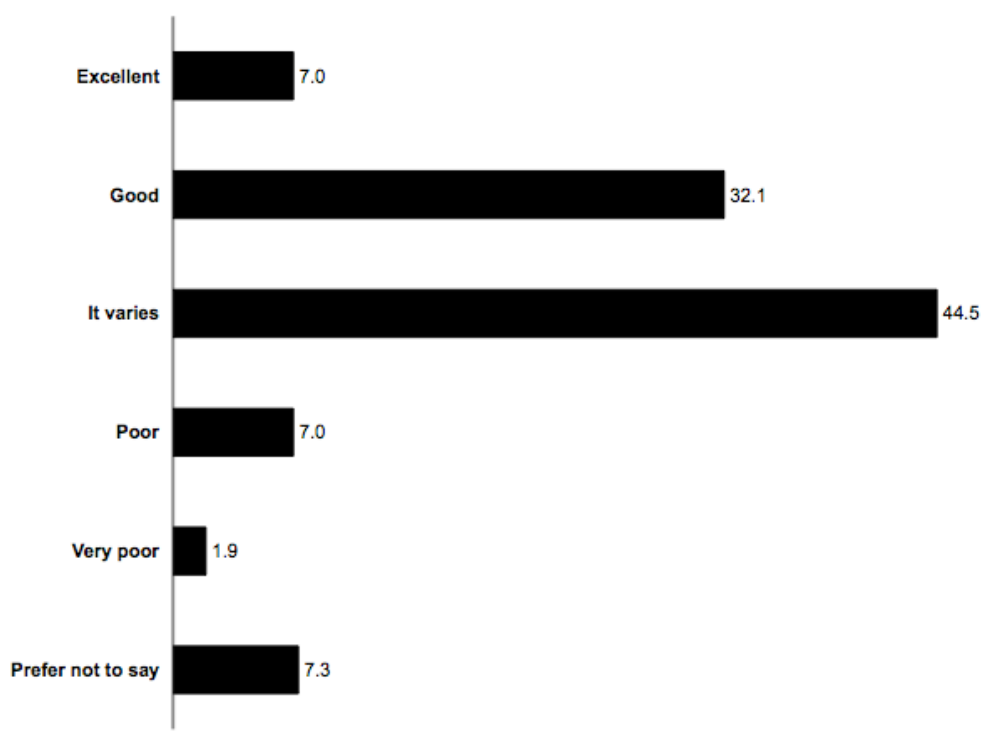

Figure 19: Satisfaction with current provision of printed library books (percentages, $n=I, 646$ )

Overall, satisfaction levels among the UCL community regarding library provision are very high: $41 \%$ of those expressing an opinion find provision to be 'excellent' or 'good', only 8\% 'poor' or 'very poor'. But it is also clear that satisfaction and dissatisfaction are highly granular, with 
significant differences by gender ${ }^{28}$ (men are generally less satisfied), age ${ }^{29}$ (satisfaction increases with age), broad subject ${ }^{30}$ (there is greater dissatisfaction in engineering and the sciences), and status $^{31}$ (part-timers are less satisfied). The next two Figures (20-2I) illustrate just some of the complex interactions between these demographics again to make the point that we should not treat headline findings as necessarily being generally applicable across the board.

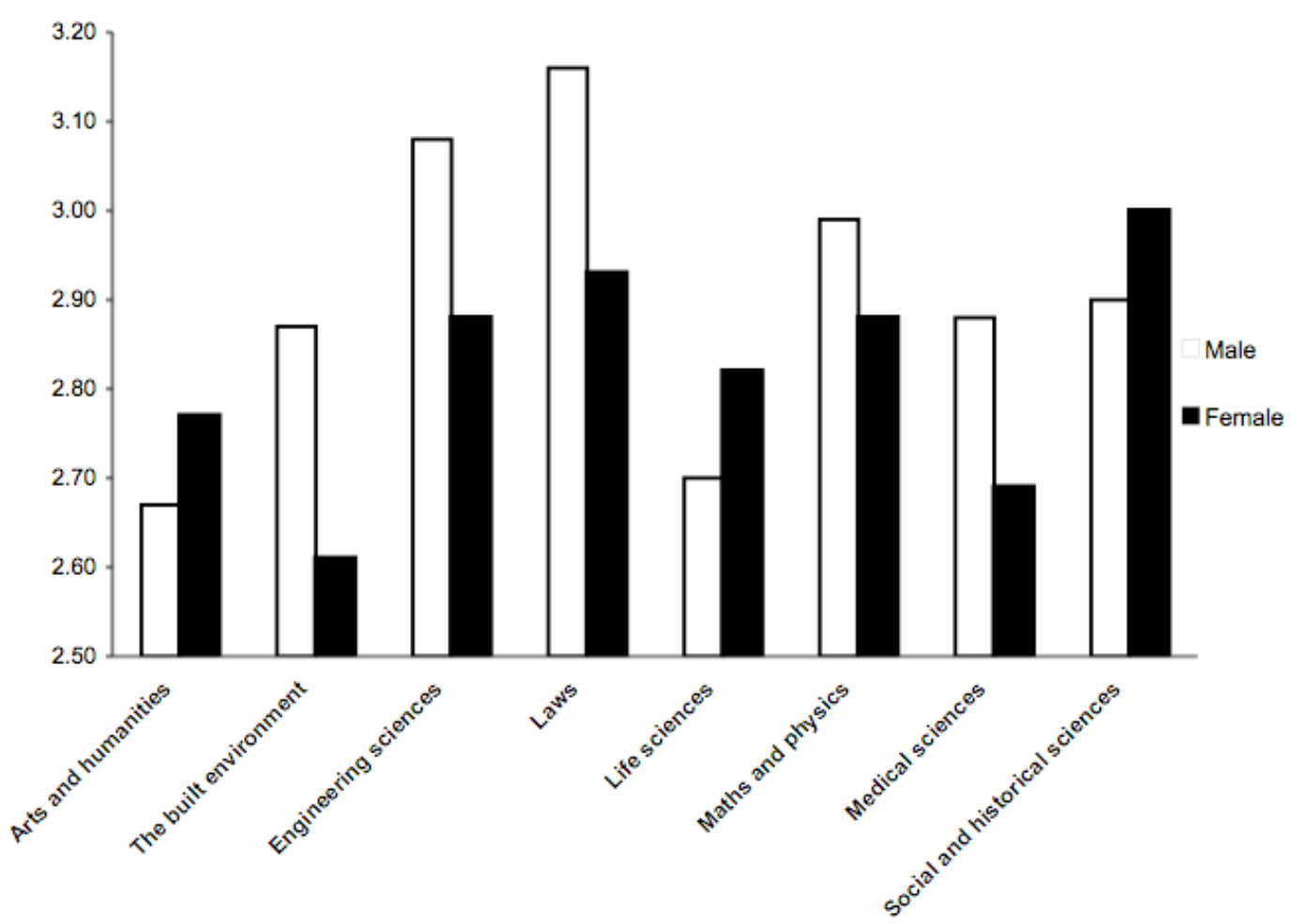

Figure 20: Satisfaction with current provision: gender/subject interactions (mean values)

28 ANOVA F $=5.92$, d.f. $=1$, distribution significant at the $5 \%$ level

29 ANOVA F $=2,64$, d.f. $=6$, distribution significant at the $5 \%$ level

30 ANOVA $F=2.19$, d.f. $=8$, distribution significant at the $5 \%$ level 


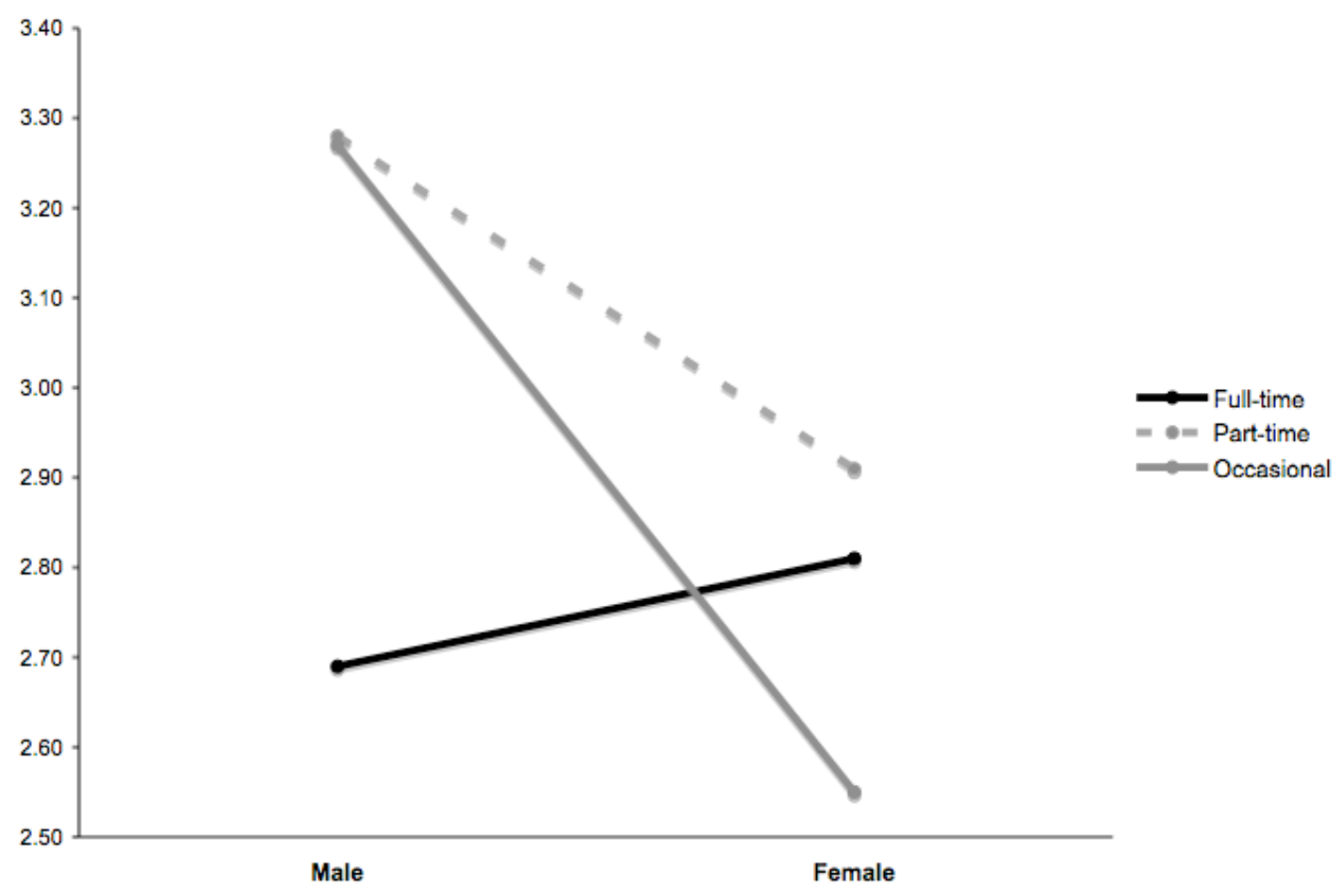

Figure 2I: Satisfaction with current provision: gender/status interactions (mean values)

These figures highlight particular local hotspots of low satisfaction: for example, men in engineering and in the mathematical and physical sciences (Figure 20, upper left) and part-time males (Figure 2I, upper left) that we might otherwise overlook.

Awareness of e-book library provision

The next question explored levels of awareness of the (then current) e-book provision made by UCL Library Services (Figure 22). 


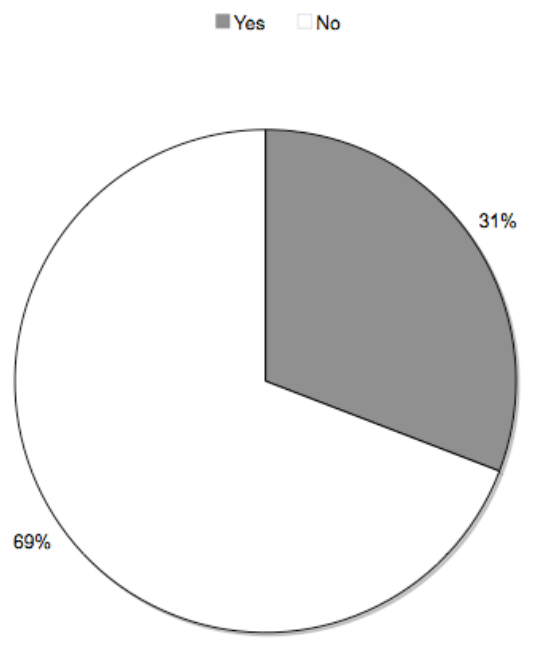

Figure 22: Awareness of $U C L$ e-book provision $(n=I, I 58)$

Students, especially at Masters' (4I\%) or undergraduate (34\%) level are much more aware of elibrary book provision than are academic (24\%) and research staff $(21 \%)$. Amongst the faculties (faculty and students), engineering sciences (4I\%) and social and historical sciences (38\%) are the most e-book aware, life sciences (22\%) and mathematical and physical sciences (20\%) the least. Surprisingly perhaps there are no significant differences between full- and part-time members of the UCL community.

\section{Library e-book awareness channels}

For those faculty and students that were aware of library provision, a subsidiary question revolved around the channels by which they had found out about those e-books in the first place (Figure 22). 


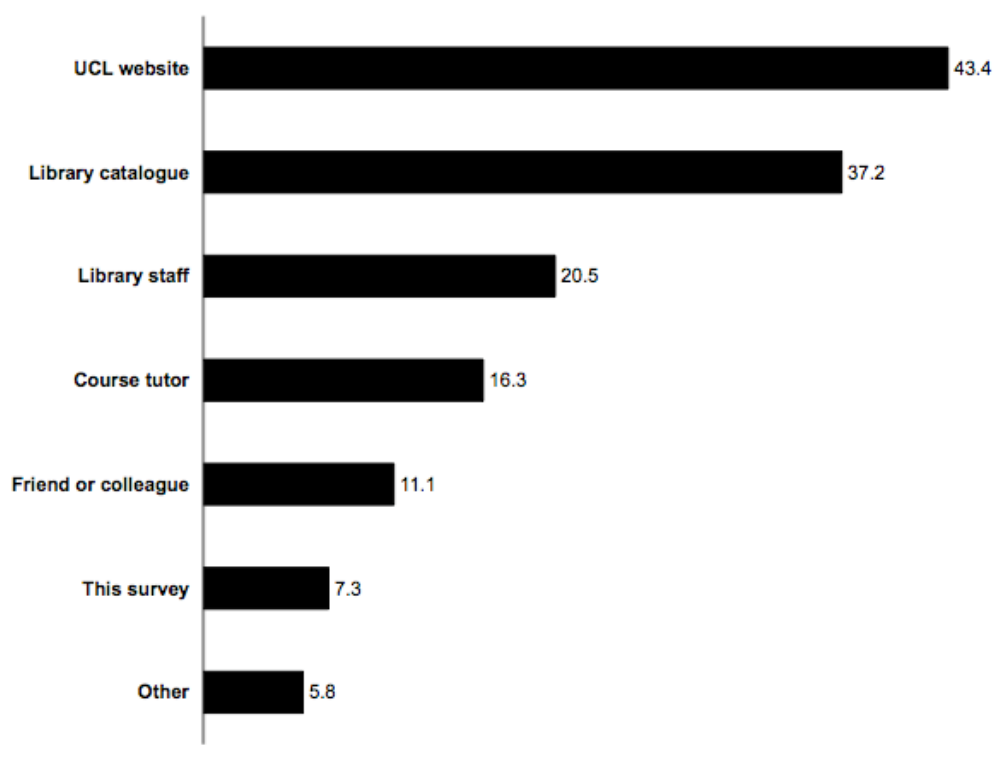

Figure 23: Library e-book awareness channels (percentages, $n=521$ )

The main channels forming initial awareness of UCL Library Service e-books were the website and library catalogue. This is especially so for men: staff briefings and course tutors were more effective awareness-raising channels for women. Course tutors play a vital role: $68 \%$ of undergraduates said that they found out about UCL provision this way.

\section{Library e-book marketing preferences}

Regardless of whether they had any e-book experience, or whether or not they knew about local UCL library provision, all respondents were asked at this point what they felt would be the single most effective way to get the message out about e-library books. 


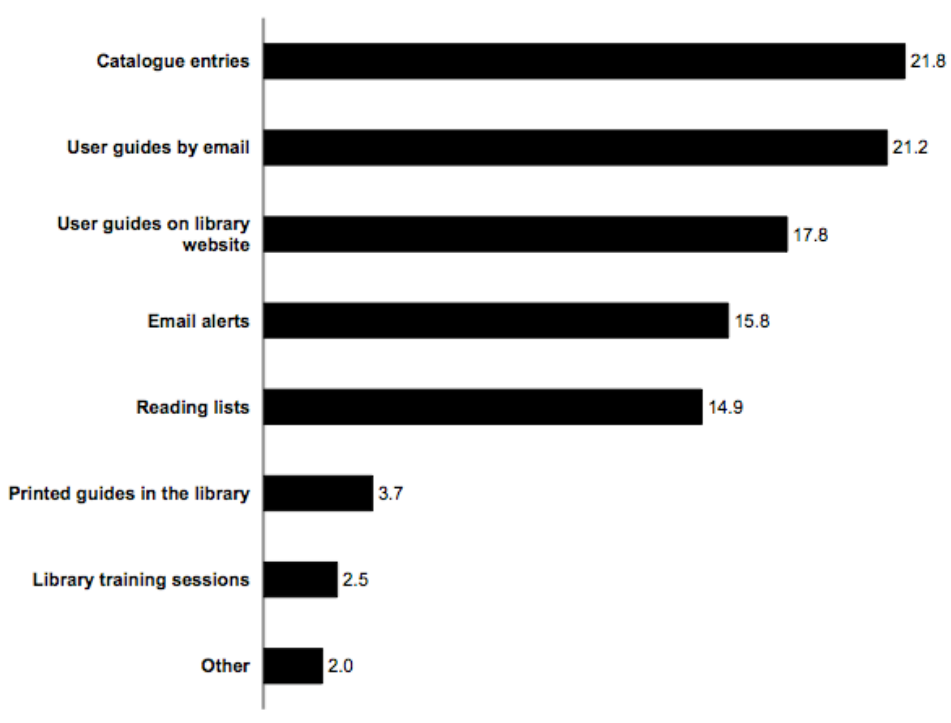

Figure 24: Library e-book marketing preferences (percentages $n=I, 662$ )

Overall, the most effective marketing channels for e-books in this context are likely to be information on the library website and email user guides, but more precise targeting for different groups may well pay dividends. Within this broad picture, the survey findings suggest that staff would very much welcome a user guide posted on the library website, that undergraduates would benefit enormously from making sure that e-books are included and signposted on reading lists, and that graduate students are able to access a printed information guide in the library.

\section{Some early conclusions}

This survey reveals a substantial level of interest in and use of e-books in at least one major academic institution in the UK. Demand is currently being satisfied by a mixed market of suppliers, with libraries playing a key, but by no means an exclusive role, in satisfying the needs of e-readers.

Diversity is a common theme in this survey, as in so much of our recent work and attitudes towards e-books, print titles, and libraries vary, sometimes considerably so, by age, academic status, and (especially) by subject. Self-reporting on many of the issues we investigated appears to be significantly gendered, even when confounding variables like subject and academic status are 
taken into consideration. Men, so they tell us, are really keen on e-books and much less dependent upon formal library systems and services: they prefer to be self-sufficient and to go their own way. A key research question for us (and for the publishing and library communities at large) is whether information behaviour, in real life, really is as gendered as our respondents tell us. If so, and if self-reported attitudes and perceptions really do translate into actions, then the information professions will have a lot to think about.

One of the most interesting lines of future inquiry opened up by this survey is the notion that book discovery behaviour is highly patterned and that readers may use different underlying strategies at different times to meet different kinds of information need. This could have major implications for publishers and booksellers as well as libraries.

All of these issues and more will be explored in the next phase of SuperBook.

lan Rowlands, David Nicholas, Hamid R. Jamali and Paul Huntington

CIBER

School of Library, Archive and Information Studies

Henry Morley Building

University College London

Gower Street

London WCIE 6BT, UK 